\title{
A relação entre desenvolvimento humano e aprendizagem: perspectivas teóricas
}

\author{
Crístia Rosineiri Gonçalves Lopes Corrêa \\ Universidade Federal de Juiz de Fora - Juiz de Fora - MG - Brasil
}

\section{Resumo}

O artigo tem como objetivo apresentar a relação entre desenvolvimento e aprendizagem nas teorias de Piaget e Vygotsky. Piaget confere ênfase aos conceitos de ação e de coordenação das ações. Em Vygotsky, a ênfase é colocada no conceito de Zona de Desenvolvimento Próximo. Ademais, objetiva problematizar o lugar de uma não usual perspectiva psicanalítica de Freud nesse contexto conceitual da relação entre desenvolvimento e aprendizagem no sentido de evidenciar a possibilidade de tal discussão psicanalítica nesse âmbito. Apresenta algumas possíveis contribuições da leitura psicanalítica dentro do tema trabalhado concernentes às consequências da sexualidade infantil para o acesso ao ato de aprender. A partir do trabalho com conceitos desenvolvidos em determinado momento teórico do autor, utilizando-se de literatura publicada acerca do tema, conclui que, embora comportem diferenças significativas, as três perspectivas explicitam a importância do desenvolvimento no tocante à aprendizagem.

Palavras-chave: Psicologia do Desenvolvimento; aprendizagem escolar; teorias.

\section{The relationship between human development and learning: theoretical approaches}

\begin{abstract}
The article aims to present the relationship between development and learning in the theories of Piaget and Vygotsky. Piaget emphasizes the concepts of action and coordination of actions. In Vygotsky, the emphasis is placed on the concept of Zone of Proximal Development. In addition, it aims to problematize the place of an unusual psychoanalytic perspective of Freud in this conceptual context of the relation between development and learning in order to highlight the possibility of such a psychoanalytic discussion in this scope. It presents some possible contributions of the psychoanalytic reading within the theme worked on the consequences of child sexuality for the access to the act of learning. From the work with concepts developed in a certain theoretical moment of the author, using published literature on the subject, concludes that, although they carry significant differences, the three perspectives explain the importance of development in relation to learning.
\end{abstract}

Keywords: Developmental Psychology; school learning; theories.

\section{La relación entre desarrollo humano y aprendizaje: perspectivas teóricas}

\section{Resumen}

El artículo tiene como objetivo presentar la relación entre desarrollo y aprendizaje en las teorías de Piaget y Vygotsky. Piaget confiere énfasis a los conceptos de acción y de coordinación de las acciones. En Vygotsky, el énfasis es colocada en el concepto de Zona de Desarrollo Próximo. Además, objetiva problematizar el lugar de una no usual perspectiva psicoanalítica de Freud en ese contexto conceptual de la relación entre desarrollo y aprendizaje en el sentido de evidenciar la posibilidad de tal discusión psicoanalítica, en ese ámbito. Presenta algunas posibles contribuciones de la lectura psicoanalítica dentro del tema trabajado concernientes a las consecuencias de la sexualidad infantil para el acceso al acto de aprender. A partir del estudio con conceptos desarrollados en determinado momento teórico del autor, utilizando se de literatura publicada acerca del tema, concluye que, aunque comporten diferencias significativas, las tres perspectivas explicitan la importancia del desarrollo en lo tocante al aprendizaje.

Palabras clave: Psicología del Desarrollo; aprendizaje escolar; teorías. 


\section{Introdução}

No presente artigo temos como objetivo apresentar três perspectivas teóricas, no âmbito da relação entre desenvolvimento humano e aprendizagem, recortando conceitos desenvolvidos em determinados momentos teóricos do autor deste artigo. Consideramos este estudo pertinente na própria medida em que a relação entre desenvolvimento humano e aprendizagem constitui-se em uma matéria de significativa relevância no campo da interface entre Psicologia e Educação, configurando, pois, uma grande contribuição que a Psicologia pode conferir ao campo educacional. Nesse contexto conceitual, destacam-se as perspectivas teóricas de Jean Piaget e de Lev Vygotsky acerca da relação entre desenvolvimento e aprendizagem.

Sabemos que nesse contexto toma lugar também uma teoria desenvolvimentista clássica orientada por uma perspectiva psicanalítica, a partir da qual é extraída outra leitura da relação entre desenvolvimento e aprendizagem; mas sabemos igualmente que, a despeito de uma inicial adoção de uma perspectiva de cunho um tanto desenvolvimentista nos anos 1930, a orientação psicanalítica lacaniana, a partir dos anos 1950, passa a reivindicar como algo problemático falar de uma perspectiva desenvolvimentista a partir da psicanálise de Sigmund Freud. A perspectiva psicanalítica a ser recortada no presente artigo é justamente calcada em uma leitura dos textos freudianos de orientação lacaniana a partir dos anos 1950, embora o percurso do artigo não venha a se aprofundar em referências explícitas aos textos de Jacques Lacan.

No entanto, a despeito dessa orientação, que a princípio seria antidesenvolvimentista, argumentamos que é possível extrair algumas contribuições da abordagem freudiana da sexualidade infantil para o acesso ao ato de aprender e que, a partir dessas contribuições, é possível falar de uma relação entre desenvolvimento e aprendizagem do adotado ponto de vista psicanalítico. Com a ressalva, é preciso dizer, de se configurar em um desenvolvimento que leve em conta o real, isto é, aquilo que, segundo Lacan, configura o impossível de saber, de ser simbolizado; aquilo que vulnerabiliza e obstaculiza todo e qualquer progresso idealizado.

\section{A relação entre desenvolvimento e aprendizagem na teoria de Piaget}

Piaget (1964/2014) estrutura sua explicação do desenvolvimento cognitivo e afetivo fundado na ação impulsionada por um motivo, que se traduz sempre sob a forma de uma necessidade que manifesta uma situação de um desequilíbrio. Aqui, cabe introduzir as noções de Esquema, Assimilação e Acomodação. Os Esquemas são estruturas mentais referentes a um todo organizado, estando relacionados com uma estrutura cognitiva específica. AAssimilação concerne à capacidade de o sujeito incorporar objetos da cognição à sua estrutura cognitiva. A Acomodação concerne ao reajustamento ocorrido na estrutura de modo a poder incorporar o novo objeto. $O$ equilíbrio entre a assimilação e a acomodação recebe o nome de equilibração. Em todo processo de interação do sujeito com o objeto, os processos de Assimilação e Acomodação se encontram presentes, ora com a predominância de um, ora com a predominância de outro. Os esquemas possuem uma plasticidade dinâmica, adaptando-se à realidade de maneira a poder assimilá-la. Diante de uma situação externa, ocorre a aplicação do esquema, isto é, a ação assimiladora do sujeito inicia um ciclo de ações sobre o objeto. Se o esquema conseguir incorporar o novo objeto à estrutura previamente existente ocorre a manutenção da situação atual. Mas se o esquema não conseguir incorporar o novo objeto frente ao qual o sujeito se encontra, então o sujeito está diante de um desequilíbrio. Essa situação se coloca quando o referido ciclo de ações do sujeito sobre o objeto for seguido de ações de retorno, do objeto sobre o sujeito (Becker, 2014). A função do objeto, no processo de construção das competências cognitivas, é desequilibrar o sujeito (Becker, 2014).

O fracasso da ação desencadeia a tomada de consciência, com o sujeito procurando os pontos em que houve falha da adaptação do esquema de assimilação ao objeto. Intervém, nesse caso, o mecanismo de regulação. Sobre as regulações e a tomada de consciência, para Piaget, regular é manter, modificar ou variar a ação seguinte em função dos resultados da ação anterior. Há dois tipos de regulação: automática e ativa. São as regulações ativas que provocam a tomada de consciência. O sujeito, diante da resistência do objeto, efetua modificações em seus esquemas assimiladores "para dar conta da nova ação que sentiu ser insuficiente. Um novo ciclo de ações pode ser inaugurado se o sujeito resolver continuar e voltar a agir sobre o objeto, agora com capacidade de assimilação melhorada" (Becker, 2014, p. 110-11) (equilibração majorante). Como resultado, temos um sujeito mais capaz. "As novas construções resultam das ações do sujeito em resposta às resistências do objeto" (Becker, 2014, p. 111). Desse modo, o desequilíbrio pode ser majorante ou não. Por desequilíbrio majorante Piaget define o desequilíbrio que leva o sujeito a um processo de acomodação da estrutura cognitiva. Ocorre a modificação dos Esquemas de Assimilação de maneira a assimilar o novo objeto, mas se o objeto está muito longe das possibilidades de assimilação dos Esquemas atuais, ocorre um desequilíbrio que não é majorante. Nesse caso, o sujeito nega o objeto ou o ignora, ocorrendo então a manutenção da situação atual. Ademais, o próprio processo assimilador também faz intervir o mecanismo de regulação, desencadeando a tomada de consciência.

Dito isso, propomos, para anuançar ainda mais o conceito de ação que fundamenta o desenvolvimento da criança e do adolescente na perspectiva piagetiana, falar de experiência. Existem dois tipos de experiência: a física e a lógico-matemática. A experiência física consiste na ação sobre os objetos, retirando deles qualidades que são intrínsecas a eles ou ainda que existem neles antes da ação do sujeito sobre eles. Já a experiência lógico-matemática consiste na ação sobre os objetos, retirando não deles, mas da ação e das coordenações do sujeito, características que são próprias dessas coordenações. Por conseguinte, de acordo 
com Becker (2013), experiência na perspectiva piagetiana não é submissão passiva aos objetos, mas uma ação sobre eles que venha modificá-los ou transformá-los. Ação que se compõe das duas já referidas ações entre si complementares: a assimilação e a acomodação. A experiência física e a experiência lógico-matemática colocam em jogo o processo de abstração, que consiste em retirar algo de alguma coisa a partir do interesse do sujeito. Assim, o fator afetivo - interesse - está no cerne do processo de abstração (Becker, 2013). Encontramos em Piaget dois grandes tipos de abstração: a empírica e a reflexiva ou reflexionante.

Enquanto a abstração empírica é concernente à experiência física: abstração por meio da qual o sujeito retira qualidades dos objetos ou das ações nas suas características materiais, dos observáveis; a abstração reflexionante é a abstração em jogo na experiência lógico-matemática, ou seja, é a abstração por meio da qual o sujeito retira qualidades das coordenações das ações próprias que não podem ser observadas, extrai delas determinadas qualidades e faz uso delas para outros fins, com o intuito de reconstruir essas qualidades em um novo patamar, gerando novas formas. A abstração reflexionante desdobra-se em abstração pseudoempírica e abstração refletida.

A abstração pseudoempírica é a abstração que é em tudo uma abstração empírica. No entanto, o que por meio dela o sujeito retira do objeto não está no objeto, mas nas coordenações das ações do sujeito. Exemplo: este lápis é menor que aquele. A qualidade "menor que" não está no lápis, e sim o sujeito que o caracterizou. É, portanto, uma qualidade da ação do sujeito sobre o lápis e não do lápis. O novo conhecimento é tirado por abstração, não das propriedades do objeto, e sim da organização introduzida pelo sujeito (Becker, 2013). Já a abstração refletida ocorre quando a reflexão torna-se obra do pensamento, nos níveis superiores. A reflexão que dá origem à novidade pode se manter por muito tempo apenas no nível da ação e sem tomada de consciência. Pode-se, dessa forma, conceituar as abstrações refletidas como o resultado de uma abstração reflexionante quando essa se torna consciente. Esse tipo de abstração confere ao sujeito estabelecer relações implicativas entre os fatos, sem intermediação do real. A partir do enfoque no conceito teórico de coordenação das ações, Piaget (1964/2014) introduz os estágios do desenvolvimento da criança e do adolescente, que não descreveremos, tendo em mente que as duas funções superiores da inteligência e da afetividade são indissociáveis em toda conduta e que elas tendem a um equilíbrio móvel.

Com a abordagem piagetiana do desenvolvimento cognitivo e afetivo calcado na ação, fica explicitado que, embora Piaget não tenha sido efetivamente um pedagogo, seu pensar epistêmico e sua psicologia genética muito contribuíram para a elaboração de uma pedagogia ativa. 0 objetivo dessa pedagogia, segundo Piaget, é levar a criança a atingir o seu pleno desenvolvimento cognitivo. Para Piaget (1970), os conhecimentos derivam da ação no sentido já abordado. E assim o sendo, "conhecer um objeto é agir sobre ele e transformá-lo" (p. 30). A natureza da construção do conhecimento na Epistemologia piagetiana é ativa. Isso porque a criança, o adolescente/aluno são sujeitos ativos de seu desenvolvimento cognitivo. Ele conhece, compreende, inventa, cria, constrói e reconstrói. A natureza ativa da construção do conhecimento implica a existência de métodos ativos na aprendizagem escolar. Tais métodos são descritos como aqueles que conferem especial destaque à pesquisa espontânea do aluno, requerendo que toda verdade a ser adquirida seja reinventada por ele e não apenas transmitida.

Para que ocorra a aprendizagem da criança e do adolescente, é necessário haver interação entre sujeito e objeto, pois o conhecimento é elaborado por meio de uma construção contínua, isto é, ele não se encontra pronto e acabado nem no meio exterior nem no sujeito do conhecimento. Antes, o conhecimento se dá na relação entre eles. Na tese central do construtivismo: "o conhecimento não tem sua gênese nem no sujeito nem no objeto, mas resulta das interações entre o sujeito e objeto pela ação do sujeito" (Collares, 2003, p. 49). Na relação entre o sujeito do conhecimento e o objeto a ser conhecido, há a presença impreterível da ação.

Desse modo, o aluno aprende porque, como sujeito ativo, age sobre os conteúdos escolares, assimilando o que a professora propõe. Para Becker (2013), na perspectiva piagetiana, o aluno precisa amadurecer, mas a maturação não é suficiente. Precisa ser estimulado - a estimulação tem que estar presente na escola. Mas é a ação do aluno que transformará tal material estimulante verdadeiramente em estímulo. Ação que não pode ficar entregue ao acaso: precisa ser orientada pelo professor. O professor como colaborador há de saber fazer uso da atividade da criança para promover a sua aprendizagem. É mais que um conhecimento aprofundado sobre o conteúdo a ser ensinado: é saber relacioná-lo às possibilidades da criança (Vergnaud, 2009).

Todavia, a ação do educador de criar situações para que o sujeito aprendiz possa conhecer é uma ação calcada na ciência e no respeito pelo seu desenvolvimento cognitivo, pois o que se transmite através de instrução é bem assimilado pela criança quando representa, de fato, uma extensão de algumas de suas construções espontâneas (Piaget, 1970). Sobre isso, é muito importante ratificar que, para Piaget, o desenvolvimento espontâneo não significa maturação nem significa negar a influência e a necessária ação sistemática do meio escolar. Antes, significa que, no estudo do desenvolvimento das noções científicas, toma lugar a necessidade da consideração "do processo da construção das operações pelo sujeito do conhecimento, que consistem em ações interiorizadas que se fazem reversíveis e se coordenam entre si em sistemas de conjunto sujeitos a leis bem definidas" (Dongo Montoya, 1995, p. 36). Nessa direção, a escola deve partir dos esquemas de assimilação da criança e do adolescente, propondo atividades desafiadoras que provoquem desequilíbrios e reequilíbrios sucessivos (equilibração majorante), conduzindo o aluno a novas descobertas e à construção do conhecimento. Na aprendizagem, pois, ao assimilar, o sujeito depara-se com novidades que perturbam seu equilíbrio. Por meio da autorregulação, recupera o 
equilíbrio perdido, mas construindo algo novo, para que o equilíbrio se restabeleça (Becker, 2013).

Segundo Becker (2013), a abstração reflexionante e seus desdobramentos, a abstração pseudoempírica e a abstração refletida, introduzem a ideia de que o sujeito não adquire nada a não ser por meio da sua atividade sobre o mundo (ação assimiladora) que se desdobra em atividade sobre si próprio (ação de acomodação). Essas ações, complementares entre si, constituem as capacidades cognitivas, ponto de partida de toda aprendizagem. Por conseguinte, nada é dado ao sujeito no que tange às suas competências cognitivas. Tudo é construído. Construções que tomam lugar na dependência das possibilidades de assimilação e do interesse (fator afetivo) do indivíduo. Logo, para Piaget, a aprendizagem é um epifenômeno do desenvolvimento. "A aprendizagem depende em tudo do desenvolvimento; suas possibilidades são abertas ou limitadas pelo desenvolvimento cognitivo" (Becker, 2013, p. 83) e afetivo.

Por fim, importa assinalarmos algo acerca do referido interesse que, conjuntamente com a necessidade, configuram substancialmente o desenvolvimento afetivo na perspectiva piagetiana. Afinado com o escolanovismo, para Piaget (1964/2014), a aprendizagem não ocorre sem que haja interesse do próprio indivíduo, no que o interesse é regulador de energia. A intervenção do interesse mobiliza as reservas internas de força de tal modo que ocorre a sensação de facilidade e a diminuição da fadiga quando o conhecimento proposto interessa ao aluno. Para ele, os escolares obtêm um rendimento melhor quando o ensino apela para seus interesses e quando os conhecimentos que são propostos correspondem às suas necessidades.

\section{A relação entre desenvolvimento e aprendizagem em Vygotsky}

A Psicologia Histórico-Cultural, que tem em Vygotsky o seu iniciador e um de seus principais representantes, aborda o desenvolvimento psicológico da criança como fenômeno histórico intimamente ligado às condições objetivas da organização social, sendo fundamentais a consideração do lugar ocupado pela criança nas relações sociais e as condições históricas concretas nas quais é desenrolado o seu desenvolvimento (Pasqualini, 2009). Vygotsky argumenta, pois, que tal desenvolvimento não é determinado por leis naturais de caráter universal. Desse modo, Vygotsky (1995) evidencia a subordinação dos processos biológicos ao desenvolvimento cultural. Tal relação entre o plano biológico e o plano cultural é delineada em termos de uma diferenciação das funções psicológicas elementares, funções comuns a homens e animais, tais como a atenção e a memória involuntárias, das funções psicológicas superiores, funções exclusivamente humanas que possuem gênese fundamentalmente cultural e não biológica, tais como a atenção voluntária e o pensamento abstrato.

O que permite a compreensão do desenvolvimento das funções psicológicas superiores é o conceito de media- ção. A relação do homem com o mundo físico e social é sempre mediada, o que a torna mais complexa. Esses elementos mediadores são de naturezas distintas e referem-se ao uso de instrumentos e de signos. O desenvolvimento dessas funções ocorre a partir do uso de signos que são instrumentos especificamente humanos, isto é, mediadores de natureza psicológica que tornam as ações humanas mais complexas e sofisticadas, produzindo novas relações com o ambiente e uma nova organização do próprio comportamento. Como exemplo, a utilização de objetos para contagem. Para Vygotsky (1995), toda função no desenvolvimento cultural da criança aparece duas vezes, em dois planos; primeiro no plano social (categoria interpsíquica), e depois no psicológico (categoria intrapsíquica).

Essa análise de Vygotsky traz implicações diretas para o ensino, na própria medida em que ressalta a dependência do desenvolvimento psicológico da criança em relação aos processos educativos. Ao concluir que as funções psicológicas superiores têm gênese fundamentalmente cultural e não biológica, aparece como evidente a necessidade de o ensino não basear-se na expectativa da maturação espontânea de tais funções e nem tomar tal maturação como condição prévia para as aprendizagens. Antes, é responsável por promover seu desenvolvimento. Ademais, ao planejar seu trabalho pedagógico, o professor precisa considerar que ele é um dos mediadores da cultura socialmente valorizada, situando-se entre seu aluno e o conhecimento escolar, com a tarefa de conduzir o primeiro a se apropriar do segundo.

De acordo com Vygotsky (1996), o desenvolvimento psicológico é caracterizado pela alternância de períodos relativamente longos e estáveis e de curtos períodos de crise. Enquanto nos períodos estáveis o desenvolvimento ocorre principalmente a partir de mudanças microscópicas da personalidade da criança acumuladas até determinado limite, se manifestando mais tarde como uma súbita formação qualitativamente nova, nos períodos críticos, mudanças bruscas e fundamentais na personalidade são produzidas em tempo relativamente curto, desembocando em uma reestruturação das necessidades e motivos da criança e de sua relação com o meio.

Para Vygotsky, em cada etapa do desenvolvimento psicológico da criança, encontra-se sempre uma nova estrutura da idade. A noção de estrutura da idade concerne a um conjunto de relações integrais entre funções psicológicas, focalizando as suas inter-relações, ao invés de considerá-las isoladamente. Essa noção introduz que, em cada idade, a multiplicidade das funções psicológicas que integram o processo de desenvolvimento constitui um todo único e possui uma determinada estrutura. "A estrutura de cada idade anterior transforma-se em uma nova que surge e se desenvolve à medida que ocorre o desenvolvimento da criança" (Facci, 2004, p. 75).

Ademais, para Vygotsky, em cada etapa do desenvolvimento psicológico da criança, encontra-se sempre também uma nova formação central que configura uma espécie de guia para todo o processo de reorganização da personalidade da criança sobre uma base nova. Essa nova formação é 
organizada na situação social de desenvolvimento por uma contradição básica entre as capacidades atuais da criança, as necessidades e desejos das crianças e as demandas e possibilidades do ambiente (Chaiklin, 2011). Ao tentar superar essa contradição, de modo a poder realizar sua atividade, a criança se engaja em distintas tarefas concretas e específicas interações que podem desembocar na formação de novas funções ou no enriquecimento de funções já existentes. A nova formação central "produzida em um dado período etário é consequência das interações da criança na situação social de desenvolvimento, envolvendo funções psicológicas relevantes que ainda não amadureceram" (Chaiklin, 2011, p. 665). Isso contextualiza o conceito vygotskyano de importância extrema no que concerne ao desenvolvimento psicológico: a Zona de Desenvolvimento Proximal (ZDP).

De acordo com Chaiklin (2011), o conceito de ZDP é utilizado para dois diferentes propósitos na análise vygotskyana do desenvolvimento psicológico. Um deles é identificar os tipos de funções psicológicas em maturação e as interações sociais a elas associadas necessários para a transição de um período do desenvolvimento para o seguinte; e o outro é identificar o estado atual da criança em relação ao desenvolvimento dessas funções necessárias para essa transição. O primeiro propósito configura a Zona objetiva de desenvolvimento próximo que é "objetiva" no sentido de que ela reflete as funções psicológicas que precisam ser formadas ao longo de um determinado período etário para que se forme o período seguinte. Para Chaiklin (2011), pode-se afirmar que a Zona objetiva de desenvolvimento próximo para cada período é normativa, no que reflete as expectativas e demandas institucionalizadas desenvolvidas historicamente em uma particular tradição societária de prática. Por exemplo, espera-se que crianças em idade escolar desenvolvam capacidades de raciocínio com conceitos científicos.

Segundo Chaiklin (2011), na perspectiva vygotskyana, para uma dada Zona objetiva de desenvolvimento próximo, é possível tentar avaliar o estado atual de desenvolvimento de uma criança singular em relação à Zona objetiva. De acordo com Vygotsky, as funções em maturação são as fontes de mudanças na estrutura interna de um dado período etário. Assim, procedimentos avaliativos devem estar direcionados à identificação do atual estado destas funções em maturação. Para Chaiklin (2011), a extensão em que as funções em maturação estão alcançando a estrutura do seu próximo período de desenvolvimento configura o que podemos chamar de ZDP subjetiva.

A Zona subjetiva é a avaliação do estado atual da criança em relação às funções psicológicas necessárias à transição de um nível de desenvolvimento a outro. A identificação ou avaliação da ZDP de uma dada criança ocorre por meio da imitação possibilitada pela interação entre a criança e o adulto ou uma criança mais experiente em situações de assistência na resolução de tarefas cognitivas que a criança não consegue resolver de maneira independente (Chaiklin, 2011). Imitação, na forma como é utilizada por Vygotsky, não se trata de um copiar irrefletido de ações. Antes, no novo significado que o autor confere para a imitação, esta pressupõe alguma compreensão das relações estruturais do problema que está sendo resolvido. O pressuposto fundamental é que a imitação se torna possível porque as funções psicológicas em maturação são ainda insuficientes para sustentar um desempenho independente, mas desenvolveram-se o suficiente para que uma pessoa possa entender como servir-se das ações colaborativas de outra (Chaiklin, 2011). Desse modo, se a criança não apresenta nenhuma capacidade de imitar, isso deve ser compreendido como um indicador de que as funções psicológicas relevantes não estão presentes; pois a criança só é capaz de se beneficiar de uma assistência se ela puder compreender o significado dessa assistência. E é a presença das funções psicológicas em maturação que subsidia essa compreensão (Chaiklin, 2011).

Com o conceito de ZDP, Vygotsky (2013) reivindica que o bom ensino é aquele que passa adiante do desenvolvimento e o guia, fazendo o desenvolvimento avançar. A abertura e a disponibilidade do professor para desempenhar o papel de mediador, propondo demonstrações, perguntas-guias etc. em situações de interação, são aspectos vitais para a apropriação do conteúdo. Para Pasqualini (2009), assim, a psicologia pode subsidiar a organização do ensino ao identificar o que Vygotsky denomina de prazos ótimos da aprendizagem: o período mais propício e produtivo para determinado tipo de aprendizagem. Fica, pois, evidenciado o lugar privilegiado da intervenção intencional do educador no processo de desenvolvimento da criança nessa perspectiva teórica.

Para arrematar, ainda sobre a ZDP, Vygotsky argumenta, pois, que, em se tratando de compreender o desenvolvimento intelectual futuro, a ZDP dá uma indicação melhor que a medida do desempenho independente por tocar as funções psicológicas em desenvolvimento. Para Chaiklin (2011), um maior número de funções psicológicas em maturação dá a uma criança melhores oportunidades de se beneficiar do ensino escolar. Para Facci (2004), o conceito de ZDP dirige a atenção à ideia de que o ensino deve estar focado não nas funções psicológicas existentes, mas nas funções em desenvolvimento, que são relevantes para a passagem ao próximo período de desenvolvimento, possibilitando o desenvolvimento de tais funções; uma abordagem do ensino que impulsiona o desenvolvimento, considerando este em sua dimensão prospectiva.

Mas não é todo tipo de ensino que é voltado ao desenvolvimento integral da criança. Antes, o conceito de ZDP não está ligado ao ensino de habilidades técnicas e especializadas, como andar de bicicleta (Vygotsky, 2013). O conceito de ZDP é um conceito de extrema importância para o ensino. O papel da educação e, logo, o do ensino ganham destaque na teoria de Vygotsky. O ensino é abordado como devendo realmente promover o desenvolvimento. Nesse processo, o professor tem papel destacado como mediador entre o aluno e o conhecimento, cabendo a ele intervir na ZDP dos alunos, conduzindo a prática pedagógica (Facci, 2004). Ademais, "os educadores, precisam estar atentos às peculiaridades do desenvolvimento psíquico em diferentes etapas evolutivas, para que possam estabelecer estratégias 
que favoreçam a apropriação do conhecimento científico" (Facci, 2004, p. 78) acumulado historicamente.

\section{Uma contribuição psicanalítica para a compreensão da relação entre desenvolvimento e aprendizagem}

Freud (1905/1996a) reivindica que o primeiro surgimento da vida sexual da criança ocorre entre os três e os cinco anos. Esse primeiro surgimento da sexualidade na criança apresenta como um dos resultados a atividade investigatória desse sujeito, que não é outra coisa senão a sua curiosidade sexual. $E$ isso ocorre, pois, em uma fase que coincide com a fase pré-escolar. De acordo com Freud (1908/1996b), são três os destinos para tal investigação sobre a sexualidade. A sublimação constitui a terceira alternativa das três referidas vicissitudes, sendo apenas ela que iremos recortar, por considerarmos que a sua sintética abordagem é suficiente para problematizar o que queremos acerca do destino da investigação sobre a sexualidade. Nesse processo de sublimação, ocorre um nível de escape da pulsão sexual em relação à operação de recalque. Nessa modalidade, ocorre a desvinculação dessa pulsão sexual ou libido, que teve êxito em escapar da operação de recalque, em relação aos objetos originais da investigação sexual infantil, ficando, assim, tal pulsão a serviço dos fins intelectuais. Na leitura freudiana, a possibilidade da sublimação constitui a modalidade mais favorável aos interesses intelectuais, na própria medida em que confere abertura para a dimensão intelectual.

É no período de latência, a saber, na fase compreendida entre o quinto ano de vida e a puberdade, que Freud irá abordar tal sublimação na própria medida em que é justamente na latência sexual infantil o período no qual acontece o desvio da energia sexual para outras finalidades, como a intelectual. $\mathrm{O}$ mecanismo da sublimação seria, então, o processo de desvio das forças pulsionais sexuais para novos objetos, tendo como fundamento a renúncia pulsional. No entanto, Freud fala de outro mecanismo em jogo, que está intimamente associado e é solidário à sublimação na tarefa de dessexualizar o pensamento, trata-se da necessária força inibitória que constitui obstáculo à pulsão sexual. A operacionalidade dessa força inibitória visa ao refreamento da pulsão sexual, "que escapa ao processo de sublimação" (Santiago, 2005, p. 124), reforçando essa sublimação, consolidando o processo de inibição da pulsão quanto ao seu objetivo, possibilitando dessexualizar o intelectual e, por conseguinte, a atividade intelectual da criança. Com isso, Freud deflagra a necessidade da inibição sexual.

Desse modo, na medida em que, para uma leitura psicanalítica atual, trazida aqui, o ato de aprender se acomoda na esfera do trabalho intelectual, de acordo com Santiago (2005), como consequência da abordagem freudiana da inibição, na primeira tópica, podemos compreender a dificuldade de aprendizagem em termos da inibição intelectual. E, por conseguinte, compreender tal dificuldade a partir do sexualização do pensamento e, logo, como resultado do fracasso da ação da inibição sexual, pois a curiosidade sexual precisa ser refreada para conferir abertura para o trabalho intelectual exitoso e, logo, para o acesso ao aprender. Freud indica, pois, dois tipos de inibições: uma necessária e outra patológica, que ocorre quando essa inibição necessária fracassa. Freud indica, assim, um paradoxo no nível do mecanismo da inibição (Santiago, 2005).

Dessa forma, o dito período de latência que se instaura quando tudo ocorre bem coincide com a fase de entrada da criança na escola. A partir dessa colocação de Freud, do ponto de vista psicanalítico, temos uma importante contribuição para a relação entre desenvolvimento e aprendizagem, que é a indicação do por que algo tão significativo no nível simbólico, como são a leitura e a escrita, ocorre justamente nessa fase; isto é, a indicação da importância do necessário freio sobre a excessiva curiosidade sexual da criança para a possibilidade da canalização dessa curiosidade para outros fins desbastados quanto ao teor sexual, tais como o cognitivo.

Já em seu texto Inibição, sintoma e angústia (Freud, 1926/1996c), à luz da sua segunda tópica do aparelho psíquico, dentro da matriz do mencionado paradoxo presente no mecanismo inibitório, indicada nos Três ensaios (1905/1996a), Freud argumenta que, enquanto um sintoma denota a presença de algum processo patológico, a inibição pode concernir a uma restrição normal das funções do eu, não tendo necessariamente uma implicação patológica. A partir dessa análise, conjugada à apresentada nos Três ensaios, cabe dizer de outra possível contribuição psicanalítica para a compreensão da relação entre desenvolvimento e aprendizagem: a indicação de que existem certas inibições (no presente caso: as inibições escolares) que são passageiras e inclusive necessárias para assentar $\mathrm{o}$ ato de aprender, que fazem parte do processo de aprendizagem, não configurando nenhum quadro sintomático.

Isso é muito importante, pois está na contramão da patologização excessiva. Inclusive, acerca disso, Corrêa e Pinheiro (2013) abordam esse tipo de inibição concernente à dimensão na qual ela não se confunde com o sintoma, mais especificamente a inibição na aprendizagem na qualidade de mecanismo necessário, de caráter não patológico, em termos de uma vivência própria e necessária de um período compreendido por dúvidas, hesitação e resistência; em suma, um necessário e inescapável embaraço. Ademais, as autoras estabelecem uma aproximação entre tal vivência e o tempo para compreender nas aprendizagens. Tempo para compreender, do qual nos fala Lacan (1945/1998), indicado por esse autor como o tempo que antecede e apoia o momento conclusivo na aprendizagem. Por conseguinte, as autoras indicam que a inibição necessária enquanto um dado estrutural, já cernida por Freud nos Três ensaios e retomada no referido texto Inibição, sintoma e angústia, se manifesta, no âmbito da aprendizagem, como uma vivência de embaraço que antecede e apoia o ato de aprender. Como dito, essa é uma contribuição importante da psicanálise para a relação entre desenvolvimento e aprendizagem.

Contudo, Freud (1926/1996c) argumenta que a inibição pode ser também a expressão de uma restrição ou perturbação patológica das referidas funções do eu, compor- 
tando-se como verdadeiros sintomas. Por motivos sintéticos, no âmbito das ditas perturbações patológicas das funções, recortaremos somente a análise de Freud que recai sobre o mecanismo que diz respeito ao evitamento do conflito do eu com o Superego operante na inibição patológica da função do trabalho. Esse mecanismo irá incluir um elemento próprio da lógica dessa instância (Superego) e caro para a compreensão da inibição patológica no ato de aprender que se acomoda na dimensão do trabalho intelectual: a satisfação masoquista. Logo, outra contribuição para a relação entre desenvolvimento e aprendizagem que a psicanálise pode conferir é a compreensão de mecanismos autopunitivos que podem atuar em dificuldades de aprendizagem.

Nessa direção, a partir da indicação de Freud, podemos dizer que, na inibição de caráter patológico no ato de aprender, para não incorrer em conflito com os imperativos do superego que proíbem o êxito de aceder ao ato conclusivo de aprender e o usufruto dessa aprendizagem, o eu renuncia ao desempenho normal das competências cognitivas, ao resultado do trabalho sublimado (Santiago, 2005). Isso quando a inibição na aprendizagem configura-se como um sintoma; pois, como assinalamos, Freud indica que não necessariamente a inibição na aprendizagem tem caráter patológico.

Ademais, a partir da indicação de Corrêa (2015a), pensamos que podemos compreender a necessária inibição da curiosidade sexual e o decorrente possível acesso ao desenvolvimento cognitivo, que nos indica Freud, em termos de uma relação entre o encontro com o saber não totalizante do Outro educador, isto é, a sua castração e o ato de aprender que nos indica Lacan. Importante dizer aqui, nesse ponto, que o saber do qual fala Lacan é um saber inconsciente, um saber inventado no sentido de ele não ser um saber já dado a priori, mas sim um saber inédito, surpreendente, cuja possibilidade de invenção se dá a partir do encontro do sujeito com o enigma do desejo do Outro, que anuncia a castração no seu saber. Somente a partir desse encontro com a castração no saber do Outro, introduzida pelo seu desejo enigmático, é que se funda em ato a possibilidade de a criança inventar um saber que também será um saber não totalizante. A partir daí, há uma possibilidade de apaziguamento do excesso de embaraço do sujeito com o enigma do desejo do Outro, não poucas vezes encontrado nos quadros de dificuldades de aprendizagem (Corrêa, 2015a). Embora, na psicanálise, saber e conhecimento não sejam a mesma coisa, sendo o saber da ordem subjetiva, para o que nos concerne, aqui, cumpre privilegiar que, para a compreensão psicanalítica atual trazida, não há possibilidade para a criança sair do excesso de embaraço com o material que Ihe é demandado aprender no nível do conhecimento se há excesso de embaraço com a referida castração no saber do Outro educador: ele não sabe tudo (Corrêa, 2015b).

Nesse ponto, no que tange ao recorte de possíveis contribuições da psicanálise para a compreensão da relação entre o desenvolvimento e a aprendizagem, cabe trazer o assinalamento de Corrêa e Pinheiro (2013) de que, nesse âmbito, não se trata de negar explicações à referida curiosidade excessiva da criança, e sim da tomada sob consi- deração de que é impossível explicar "tudo". Mas, mesmo sendo impossível, a despeito de tentativas, tais tentativas introduzem um saber sexual excessivo que pode emperrar a canalização para o interesse cognitivo, por exemplo. Outro e criança, ambos, em não poucos quadros de dificuldades de aprendizagem, sabem demais (Corrêa, 2015b). Trata-se de um excesso de saber que não favorece o funcionamento da lógica presente no ato desejante, incluindo aí o ato de aprender. A possibilidade da invenção de um saber inédito, não totalizante, a partir do encontro com a castração no saber do Outro, comporta nela a possibilidade do acesso ao ato de aprender.

Desse modo, outra contribuição para a compreensão da relação entre desenvolvimento e aprendizagem que pode ser extraída da interlocução atual da psicologia e da educação com a psicanálise é justamente a indicação da relevância de o educador não responder do lugar de um saber idealizado, e sim que opere nesse processo com a sua castração para que possa ocorrer a transmissão de um saber não totalizante que confira abertura para que o sujeito coloque algo próprio, para que a criança tenha espaço para inventar, produzir novos sentidos a partir da castração no saber do Outro educador transmitido a ela. Novos sentidos que não deixem de levar em conta esse real concernente à dita castração no saber do Outro educador. Assim, para falarmos de desenvolvimento a partir da psicanálise de orientação lacaniana, há de ser um desenvolvimento que leve em conta a noção de real, isto é, da castração no saber do Outro real que vulnerabiliza toda pretensão de um progresso idealizado; pois, entre outras coisas, o encontro traumático da criança com a castração no saber do Outro, ao longo de suas pesquisas sexuais, o deixando sem a resposta última para suas perguntas, fragiliza qualquer pretensão de um idealizado desenvolvimento da sexualidade infantil.

\section{Considerações finais}

No presente artigo tivemos como objetivo apresentar três perspectivas teóricas, recortando conceitos desenvolvidos em determinados momento teórico do autor. Conforme vimos, tais perspectivas recortadas comportam significativas diferenças, colocando seu acento em pontos peculiares a cada uma. A perspectiva teórica de Piaget confere ênfase aos conceitos de ação e de coordenação das ações. $\mathrm{Na}$ perspectiva teórica de Vygotsky, a ênfase é colocada no conceito de ZDP. Podemos inclusive dizer que enquanto em Piaget o desenvolvimento é tomado em sua dimensão retrospectiva na própria medida em que as possibilidades da aprendizagem são abertas ou limitadas pelo desenvolvimento (Becker, 2013), em Vygotsky o desenvolvimento é tomado em sua dimensão prospectiva, no que o bom ensino passa adiante do desenvolvimento e o direciona, promovendo o desenvolvimento das funções psicológicas superiores.

Ademais, no que tange à perspectiva psicanalítica recortada, o objetivo foi o de apresentar algumas contribuições dentro do tema trabalhado concernentes às consequências 
da sexualidade infantil para o acesso ao ato de aprender, a partir da problematização feita. Argumentamos que, a partir dessas contribuições, é possível falar de uma relação entre desenvolvimento e aprendizagem do ponto de vista psicanalítico adotado. Com a ressalva, é preciso dizer, de se configurar em um desenvolvimento que leve em conta o real, isto é, aquilo que, segundo Lacan, configura o impossível de saber, de ser simbolizado; aquilo que obstaculiza todo e qualquer progresso idealizado.

Nessa direção, podemos concluir que, embora comportem diferenças significativas, as quatro perspectivas explicitam a importância do desenvolvimento no tocante à aprendizagem. E, no caso da psicanálise, acrescente-se a diferença introduzida pela noção de real na compreensão da ideia de desenvolvimento. Vygotsky, é preciso dizer, também problematiza o desenvolvimento no que tange à vulnerabilidade da nuance evolucionista, colocando acento nas crises que permeiam o desenvolvimento. Mas não podemos dizer que tal problematização seja equivalente à problematização lacaniana. Como corolário, concluímos pela relevância das contribuições de Piaget, Vygotsky e Freud no que tange à relação entre desenvolvimento e aprendizagem.

\section{Referências}

Becker, F. (2013). Sujeito do conhecimento e ensino de matemática. Schème Revista Eletrônica de Psicologia e Epistemologia Genéticas, 5 (Edição Especial), 65-86.

Becker, F. (2014). Abstração pseudo-empírica e reflexionante. Schème Revista Eletrônica de Psicologia e Epistemologia Genéticas, 6(Número Especial), 104-128.

Chaiklin, S. (2011). A zona de desenvolvimento próximo na análise de Vigotski sobre aprendizagem e ensino. Revista psicologia em Estudo, 16(4), 659-675.

Collares, D. (2003). Epistemologia genética e pesquisa docente: estudo das ações no contexto escolar. Lisboa: Instituto Piaget.

Corrêa, C. R. G. L. (2015a). Os por quês da criança em Piaget e na psicanálise e a dificuldade de aprendizagem. Revista Ágora, 18(2), 289-303.

Corrêa, C. R. G. L. (2015b). Dificuldade de aprendizagem e saber idealizado no Outro. Psicologia USP, 26(1), 71-79.

Corrêa, C. R. G. L. \& Pinheiro, G. S. (2013). Período de latência e tempo para compreender nas aprendizagens. Psicologia em
Estudo, 18(1), 61-69.

Dongo Montoya, A. O. (1995). Sobre as raízes do pensamento e da linguagem: Vygotsky e Piaget. Cadernos de Pesquisa, 92, 26-37.

Facci, M. G. (2004). A periodização do desenvolvimento psicológico individual na perspectiva de Leontiev, Elkonin e Vigotski. Cadernos Cedes, 24(62), 64-81.

Freud, S. (1996a). Três ensaios sobre a teoria da sexualidade (vol.VII). Edição Standard Brasileira das Obras Psicológicas Completas (J. Salomão Trad.). Rio de Janeiro: Imago. (Trabalho original publicado em 1905)

Freud, S. (1996b). Sobre as teorias sexuais das crianças (vol.IX). Edição Standard Brasileira das Obras Psicológicas Completas (J. Salomão Trad.). Rio de Janeiro: Imago. (Trabalho original publicada em 1908).

Freud, S. (1996c). Inibição, sintoma e ansiedade (vol.XXIII). Edição Standard Brasileira das Obras Psicológicas Completas (J. Salomão, Trad.). Rio de Janeiro: Imago. (Trabalho original publicado em 1926).

Lacan, J. (1998). O tempo lógico e a asserção da certeza antecipada. Escritos (V. Ribeiro Trad.). Rio de Janeiro: Jorge Zahar. (Trabalho original publicado em 1945)

Pasqualini, J. C. (2009). A perspectiva histórico-dialética da periodização do desenvolvimento infantil. Psicologia em Estudo, 14(1), 31-40.

Piaget, J. (1970). Psicologia e Pedagogia. Rio de Janeiro: Forense.

Piaget, J. (2014). Seis estudos de Psicologia. Rio de Janeiro: Forense universitária. (Trabalho original publicado em 1964).

Santiago, A. L. B. (2005). A inibição intelectual na psicanálise. Rio de Janeiro: Zahar.

Vergnaud, G. (2009). A criança, a matemática e a realidade. Curitiba: Editora da UFPR.

Vygotsky, L. S. (1995). Obras escogidas (vol.III). Madrid: Visor.

Vygotsky, L. S. (1996). Obras escogidas (vol.IV). Madrid: Visor

Vygotsky, L. S. (2013). Pensamento e Linguagem. São Paulo: Martins Fontes.

Recebido em: 24/03/2016

Aprovado em: 08/09/2016

\section{Sobre a autora}

Cristia Rosineiri Gonçalves Lopes Correa (aninhacorrea2012@yahoo.com.br)

Doutorado em Educação pela Universidade Federal de Juiz de Fora (2015), Professora substituta da Universidade Federal de Juiz de Fora - MG. 